\title{
ASYMPTOTIC EXPANSIONS OF THE MULTIPLE QUOTIENTS OF GAMMA FUNCTIONS WITH APPLICATIONS
}

\author{
Tomislav Burić, Neven Elezović and RatKo Šimić
}

\begin{abstract}
Asymptotic expansions of the multiple quotients of two gamma functions are obtained and analyzed. We apply these results to the hypergeometric function and central multinomial coefficient which leads to the new approximation formulas.
\end{abstract}

Mathematics subject classification (2010): 33B15, 41A60, 33C05. efficient

Keywords and phrases: Asymptotic expansion, gamma function, wallis ratio, central multinomial co-

\section{REFERENCES}

[1] M. Abramowitz And I. A. Stegun (Eds), Handbook of Mathematical Functions with Formulas, Graphs, and Mathematical Tables, National Bureau of Standards, Applied Mathematics Series 55, 9th printing, Washington, 1970.

[2] J. Bukac, T. Burić AND N. Elezović, Stirling's formula revisited via some new and classical inequalities, Math. Inequal. Appl. 14 (2011), 235-245.

[3] T. BURIĆ AND N. ElEZoviĆ, Bernoulli polynomials and asymptotic expansions of the quotient of gamma functions, J. Comput. Appl. Math. 235 (2011), 3315-3331.

[4] T. BuRIĆ AND N. ElEZOVIĆ, New asymptotic expansions of the gamma function and improvements of Stirling's type formulas, J. Comput. Anal. Appl. 13 (2011), 785-795.

[5] T. BURIĆ AND N. ElEZOVIĆ, New asymptotic expansions of the quotient of gamma functions, Integral Transforms Spec. Funct. 23 (2012), 355-368.

[6] C. P. Chen AND T. BuRIĆ, New asymptotic expansions of the quotient of gamma functions with applications, unpublished

[7] N. Elezović, C. Giordano And J. PeČarić, The best bounds in Gautschi's inequality, Math. Inequal. Appl. 3 (2000), 239-252.

[8] A. ERdÉLYI, Asymptotic expansions, Dover Publications, New York, 1956.

[9] Y. L. Luke, The Special Functions and Their Approximations, Vol. I, Academic Press, New York, 1969.

[10] P. LuSCHNY, Approximation formulas for the factorial function $n$ !, http://www.luschny.de/math/factorial/approx/SimpleCases.html.

[11] G. NemEs, More accurate approximations for the gamma function, Thai Journal of Mathematics 9 (2011), 21-28. 